ISSN: 0514-7336

DOI: http://dx.doi.org/10.14201/zephyrus201473217229

\title{
MOLINO ROTATORIO ROMANO CON INSCRIPCIÓN TURRO PROCEDENTE DEL CASTRO DE SAN CHUIS (SAN MARTÍN DE BEDULEDO, ALLANDE, ASTURIAS)
}

\section{Roman rotary quern with inscription Turro from the hillfort of San Chuis (San Martín de Beduledo, Allande, Asturias)}

\author{
Javier SAlido Domínguez* y Ángel Villa VAldés** \\ * Escuela Española de Historia y Arqueología en Roma-CSIC. Via di Torre Argentina, 18. 00186 Roma. Correo-e: \\ pjaviers@hotmail.com \\ ** Consejería de Educación, Cultura y Deporte del Principado de Asturias. Plaza de España, 5, planta 3.a. \\ 33007 Oviedo. Correo-e: angel.villavaldes@asturias.org
}

Recepción: 24/07/2013; Revisión: 6/02/2014; Aceptación: 12/03/2014

BIBLID [0514-7336 (2014) LXXIII, enero-junio; 217-229]

RESUMEN: En este trabajo se analiza un fragmento de catillus correspondiente a un molino de grano rotatorio de época romana localizado en el castro de San Chuis (Allande, Asturias). La particularidad de este molino es que presenta una inscripción que menciona la palabra Turro. Ante las distintas posibilidades interpretativas de dicho epígrafe, planteamos como hipótesis que este término hace referencia al propietario o al usuario de dicha mola manuaria. Para la defensa de esta teoría, analizamos otros molinos con inscripción aparecidos en el mundo romano que se refieren a unidades militares concretas -contubernium, centuria, turma- en ámbito castrense o que contienen invocaciones y marcas de difícil interpretación en el mundo civil. Al no hacer mención a la organización militar, proponemos que dicha inscripción nos advierte sobre la ausencia de unidades del ejército asentadas en dicho castro o que no siguen esta jerarquía, si bien este dato no excluye que el poblado se encuentre en un ambiente ampliamente militarizado.

Palabras clave: Economía romana. Procesamiento de alimentos. Tecnología antigua. Agricultura. Epigrafía.

ABSTRACT: This paper presents an analysis of a catillus fragment corresponding to a rotary grain mill from the Roman era found in the San Chuis Fort in Allande, Asturias. One distinctive feature of this grain mill is the fact that it contains an inscription that mentions the word Turro. Among the possible interpretations of this epigraph, we advocate the hypothesis that this word designates the owner or user of mola manuaria. To support this theory, we analyze other mills with inscriptions found in the Roman world that refer to concrete military units -contubernium, centuria, turma- or prayers and other records from the civilian circles. In the absence of any military structure, we argue that this inscription indicates there were no military units present in that fort during that time, or that at least they didn't adhere to a particular military hierarchy, even though this does not refute the fact that the civilian population lived in a heavily militarized area.

Key words: Roman economy. Food processing. Ancient technology. Agriculture. Epigraphy. 


\section{Introducción}

El lugar de hallazgo del molino harinero que analizamos en este trabajo corresponde al castro del Pico San Chuis, situado en las proximidades de San Martín de Beduledo, en el concejo de Allande (Fig. 1). Este yacimiento se extiende sobre la corona de una colina a una altitud comprendida entre los 750 y 780 m (Fig. 2) y es uno de los poblados fortificados más extensamente excavados en Asturias. Al igual que sucede en otros sitios de morfología castreña en proceso de estudio en el área depósitos auríferos localizados en el entorno del castro (Fig. 3). En consecuencia, nada tiene de extraño que durante este siglo y el siguiente San Chuis ostentase un rango administrativo destacado por el cual se ejerciese desde el poblado, entre otras funciones, el control tributario del territorium asignado (Villa, 2007: 176).

No disponemos de información suficiente para valorar el efecto que la implantación romana pudo suponer sobre el caserío preexistente o sobre las estructuras defensivas. Sin embargo, por lo ocurrido en otros yacimientos puede presuponerse

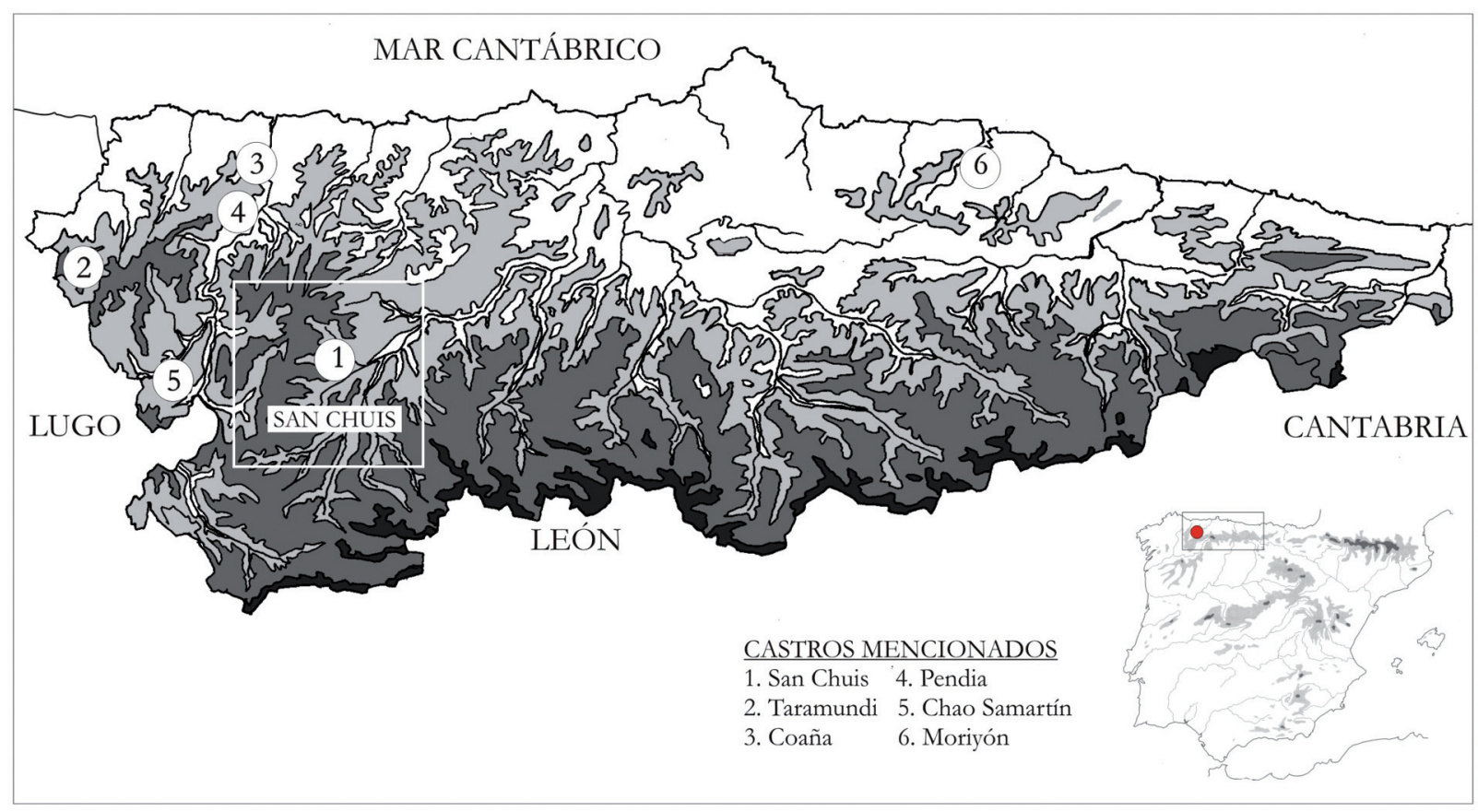

FIG. 1. Localización del castro de San Chuis y resto de poblados mencionados en el texto.

occidental de la región, las dataciones absolutas y su secuencia estratigráfica revelan una prolongada ocupación con origen probado en el Bronce final (s. VIII a. C.). Durante la Edad del Hierro el recinto acentúa su natural condición defensiva con una muralla de módulos que habrá de pervivir, con algunas reformas en su estructura y trazado, hasta época romana (Villa y Menéndez, 2011).

La presencia romana se manifiesta desde mediados del s. I d. C. en un contexto inequívocamente militarizado y marcado por la intensa actividad minera desarrollada en los extraordinarios que la construcción de algunas fortificaciones y la reforma de otras responden a exigencias militares ajenas al planteamiento defensivo indígena. $\mathrm{La}$ introducción de patrones constructivos romanos en la trama edificada es evidente y muestra ciertos paralelismos con ejemplos bien contextualizados en otros yacimientos ${ }^{1}$ (Fig. 4). Las excavaciones

${ }^{1}$ Así ocurre en el castro de Chao Samartín, donde los episodios de reformas aplicadas manu militari en el caserío y las centenarias defensas castreñas han sido datados con cierta precisión durante el s. I d. C. (Villa et al., 2006). 
de Jordá (1990) permitieron ya constatar la superposición y sustitución de las cabañas castreñas tradicionales por un modelo arquitectónico que, sin rechazar taxativamente las viejas formas oblongas o circulares, tomó como modelo preferente para las nuevas construcciones la planta de lados rectos, bien rematada en ángulo o en esquina de naipe. El área exhumada muestra con particular claridad esta divergencia de tradiciones, con un predominio casi excluyente de plantas tradicionales en las cabañas del sector $\mathrm{N}$ frente a las de traza ortogonal y aire castrense en el sector S, sobre la explanada que corona la colina. En este barrio del poblado se aprecia, además, la conformación de unidades de

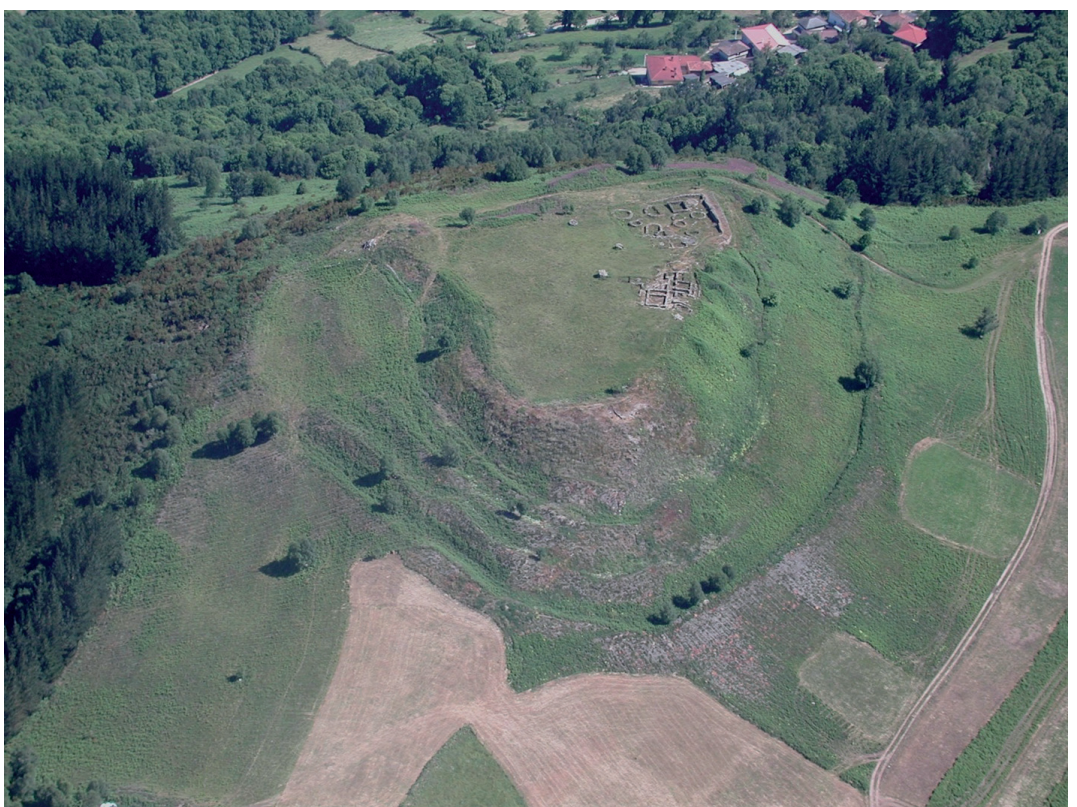

FIG. 2. Vista aérea del castro de San Chuis en el que se aprecia la divergencia formal entre el área castreña, principalmente prerromana, y el barrio superior, urbanizado durante el s. I d. C. habitación complejas, a partir

de construcciones antes independientes, mediante la clausura de vanos y cierre de calles que se incorporan de esta manera al espacio privado. No obstante, tal apreciación no deja de presentarse en términos cronológicos como intuitiva, pues se desconoce la secuencia estratigráfica que podría servirle de apoyo.

\section{El castro de San Chuis en época romana}

A diferencia de lo constatado en el área central y oriental de la región, el poblamiento castreño del occidente de Asturias conoció durante los dos primeros siglos de la era un periodo de renovado protagonismo como instrumento primordial en la reorganización de las comunidades indígenas recién conquistadas. Este insospechado impulso fue promovido por Roma en unos territorios esenciales para consolidar la reforma monetaria instaurada por Augusto que tomaba el oro y la plata como patrón de referencia. La contundencia de este episodio tiene fiel expresión en el registro arqueológico y propició una profunda distorsión de su exégesis histórica, bien con la extrapolación de los datos de época romana al mundo prerromano con el "planteamiento general de que lo indígena castreño era respetado, e incluso potenciado, por el Imperio" (Fernández-Posse, 2002: 83), bien para negar la existencia de castros en el occidente de Asturias durante la Edad del Hierro (Carrocera, 1995: 59).

El castro de San Chuis, con una generosa presencia de materiales de cronología inequívocamente altoimperial, no resultó ajeno a ello. Aunque hoy sabemos, como ya se ha dicho, de su prolongada ocupación durante el primer milenio a. C., el asentamiento conoció un periodo de gran vitalidad que necesariamente hubo de estar vinculado con la temprana puesta en marcha de las abundantes y ricas minas de oro localizadas en su entorno (Fig. 3), cuya explotación se inicia en fechas tempranas del s. I d. C., tal y como prueban las dataciones radiocarbónicas y dendrocronológicas obtenidas en explotaciones del Narcea y del Pigüeña (Villa, 2010). Una explotación a gran escala que contó con la experiencia minera de las poblaciones locales como útil apoyo, pero que hubiese sido irrealizable a gran escala sin la 
Cuenca hidrográfica del Navia/Cuenca hidrográfica del Narcea

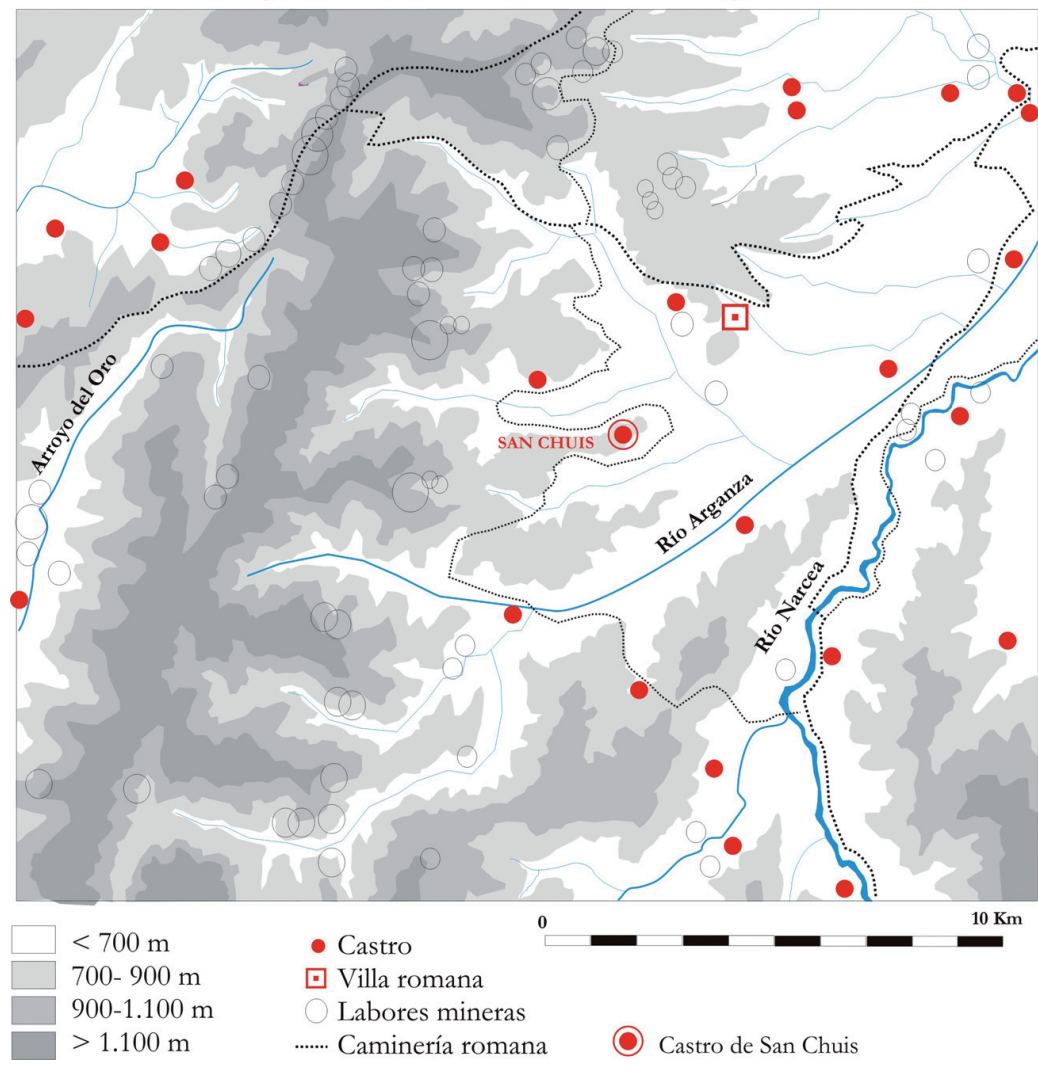

FIG. 3. Asentamientos castreños, vías y minas de oro en el entorno del castro de San Chuis (Villa Valdés, 2007).

participación de efectivos militares en su doble papel de cuerpo técnico altamente cualificado y como fuerza represiva.

$\mathrm{Al}$ igual que ocurre en otros poblados del área occidental, en San Chuis puede rastrearse la poderosa influencia del ambiente militarizado que caracterizó principalmente el s. I d. C. con la integración, en su trama edificada, de nuevas construcciones inspiradas en la arquitectura militar. También es significativo el conjunto de importaciones inequívocamente vinculadas con el abastecimiento de las tropas ${ }^{2}$ que reproducen en la

\footnotetext{
${ }^{2}$ Estudios particulares sobre el numerario, cerámicas clásicas, cerámicas de importación o determinadas innovaciones poliorcéticas han puesto de manifiesto la fuerte impronta que el ejército dejó durante el periodo de tutela militar que se prolongó hasta finales del s. I d. C. (Gil y Villa, 2006; Hevia y Montes, 2009; Villa et al., 2006).
}

secuencia estratigráfica los episodios de emergencia y progresiva sustitución de ajuares registrados en campamentos militares establecidos al sur de la cordillera durante el s. I d. C. (Carretero, 2000).

\section{Descripción, contexto arqueológico e interpretación}

La pieza corresponde a un fragmento de catillus (Fig. 5), elemento giratorio de un molino de grano fabricado en granito, con un diámetro aproximado de 440 $\mathrm{mm}$ y una altura de $145 \mathrm{~mm}$, que se halla depositado actualmente en el Ayuntamiento de Allande. Es el único ejemplar documentado con seguridad en este yacimiento. Identificado de forma casual por un grupo de visitantes entre las ruinas del yacimiento en 1984, fue dado a conocer aquel mismo año por García Linares (1984: 10) en una revista local. En dicha noticia no se aporta referencia alguna al lugar preciso del descubrimiento, si bien se puede suponer su aparición entre el material removido durante las excavaciones arqueológicas por entonces en marcha ${ }^{3}$.

Aunque la pieza no se conserva completa (Fig. 6), no cabe duda de que el fragmento aparecido corresponde a una mola manuaria, es decir, uno de los molinos rotatorios manuales muy presentes en la Península Ibérica. El movimiento rotativo

\footnotetext{
${ }^{3}$ Hay que tener en cuenta que la mayor parte de los molinos se suelen hallar en contextos habitacionales y dentro de los mismos suelen aparecer in situ las metae. Estas partes pasivas, al tratarse de piezas pesadas y poco manejables, son de difícil traslado y resisten mejor que los catilli los procesos postdeposicionales. En cambio, los catilli presentan una mayor fragilidad y menor volumen, lo que explica su fragmentación y su aparición en contextos distintos al original (Quesada et al., 2014: 103). Por ello, aunque conociésemos su lugar de procedencia, tampoco este dato arrojaría mucha luz sobre su ubicación original.
} 
ejercido mediante el uso de un posible astil de madera inserto en uno de sus lados -como se puede apreciar en el orificio conservado en el fragmento- llegó a constituir una innovación tecnológica importante en el procesado y transformación de los cereales. Este molino debió contar originalmente con dos piezas de piedra de forma circular y sección variada, encajadas entre sí por planos inclinados y enlazadas por un eje vertical. La pieza pasiva inferior -meta-, que no se conserva, permanecería estática, mientras que la superior y activa -catillus-, que aquí presentamos, giraba apoyada sobre la anterior.

La reconstrucción realizada sobre el funcionamiento de molinos muy similares al asturiano -como el encontrado en Mahdia

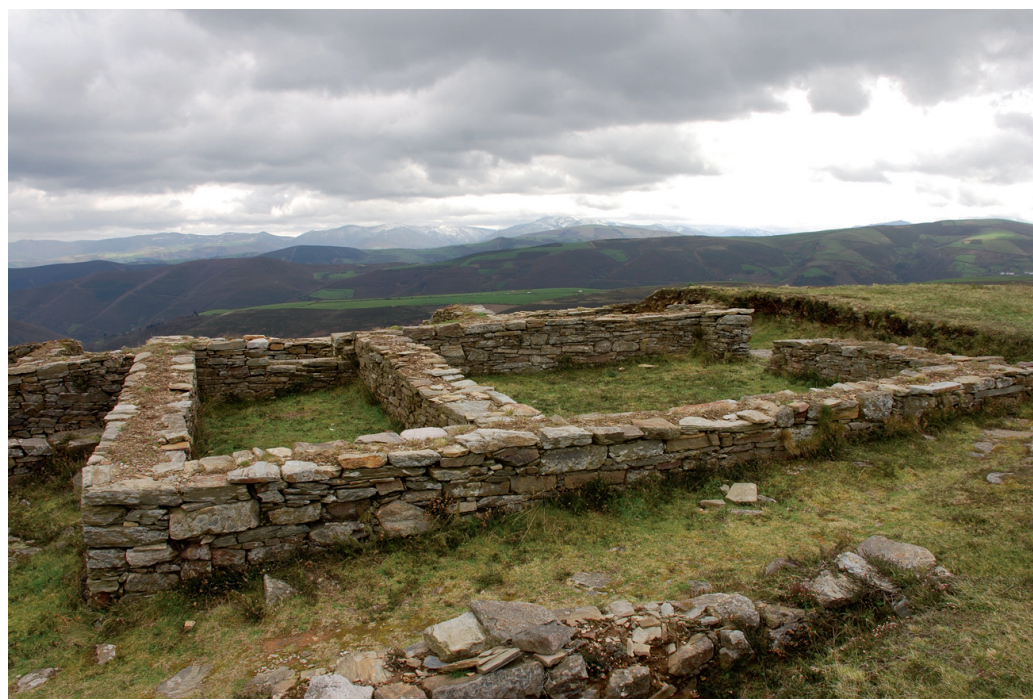

FIG. 4. Edificio altoimperial instalado sobre la explanada superior del asentamiento. Responde a un tipo de arquitectura frecuente en los castros del occidente asturiano que se vincula con tipos constructivos de tradición militar.
(Túnez), de mediados del s. I a. C.- nos informa sobre la posible colocación de un eje vertical de hierro en el orificio central de la meta (Fig. 7) que facilitaría el movimiento rotatorio (Baatz, 1994: fig. 12; Guérin, 1999: 89); en nuestro caso pensamos que el eje podría ser de madera pues no se han hallado evidencias del mismo. Aunque el lugar de origen de estos molinos rotatorios iniciales nos es desconocido por el momento ${ }^{4}$, es cierto que pronto se difundieron rápidamente por el Mediterráneo por las ventajas que ofrecen para la molturación del grano, siendo este que analizamos uno más de la amplia nómina de molinos ya aparecidos en Hispania.

Como se ha indicado en un estudio reciente sobre el Castro de Coaña, donde las piezas molares son especialmente abundantes (Villa, 2013:

${ }^{4}$ Aunque se desconoce el lugar originario de este tipo de molino, se ha planteado su inicio en las comunidades del NE de la Península Ibérica del s. V a. C. (Alonso, 1997), pero también se ha propuesto un origen cartaginés a partir de un fragmento de molino de mano giratorio datado en el s. VI a. C. (Morel, 2001). Ya de época clásica se conoce el primer molino rotatorio en Grecia datado a partir del s. III a. C. (Brunet, 1997; Curtis, 2001: 288-289).
156), de los comentarios de Estrabón relativos al consumo habitual entre los pueblos norteños de pan de bellota (III, 3, 7) llegó a concluirse, como para el del resto de molinos reconocidos en ambiente castreńo, su empleo en la trituración de este fruto, que una vez seco y panificado podía conservarse largo tiempo. Sin embargo, los ensayos experimentales demuestran que estos molinos difícilmente pudieron servir a tal fin, pues ni la forma y ni el encaje de las piedras permite el flujo de la bellota hacia la zona de abrasión (Oliveira et al., 2007: 124), resultando por ello ingenios ineficaces en su molienda, tarea para la que resultarían más apropiados los molinos de vaivén o los grandes morteros de cazoleta. Así pues, la molienda de cereal parece el uso más probable para la pieza de San Chuis 5 .

${ }^{5}$ El uso más extendido de este tipo de molinos es la trituración de grano, aunque los documentados en otros yacimientos se han interpretado como mecanismos empleados para moler productos vegetales o animales (Watts, 2011: 343) o para tareas metalúrgicas (Risch, R. [1995]: Recursos naturales y sistemas de producción en la Península Ibérica entre 3000 y 1000 a.n.e. Tesis doctoral presentada en 1995 en la Univ. Autónoma de Barcelona). 

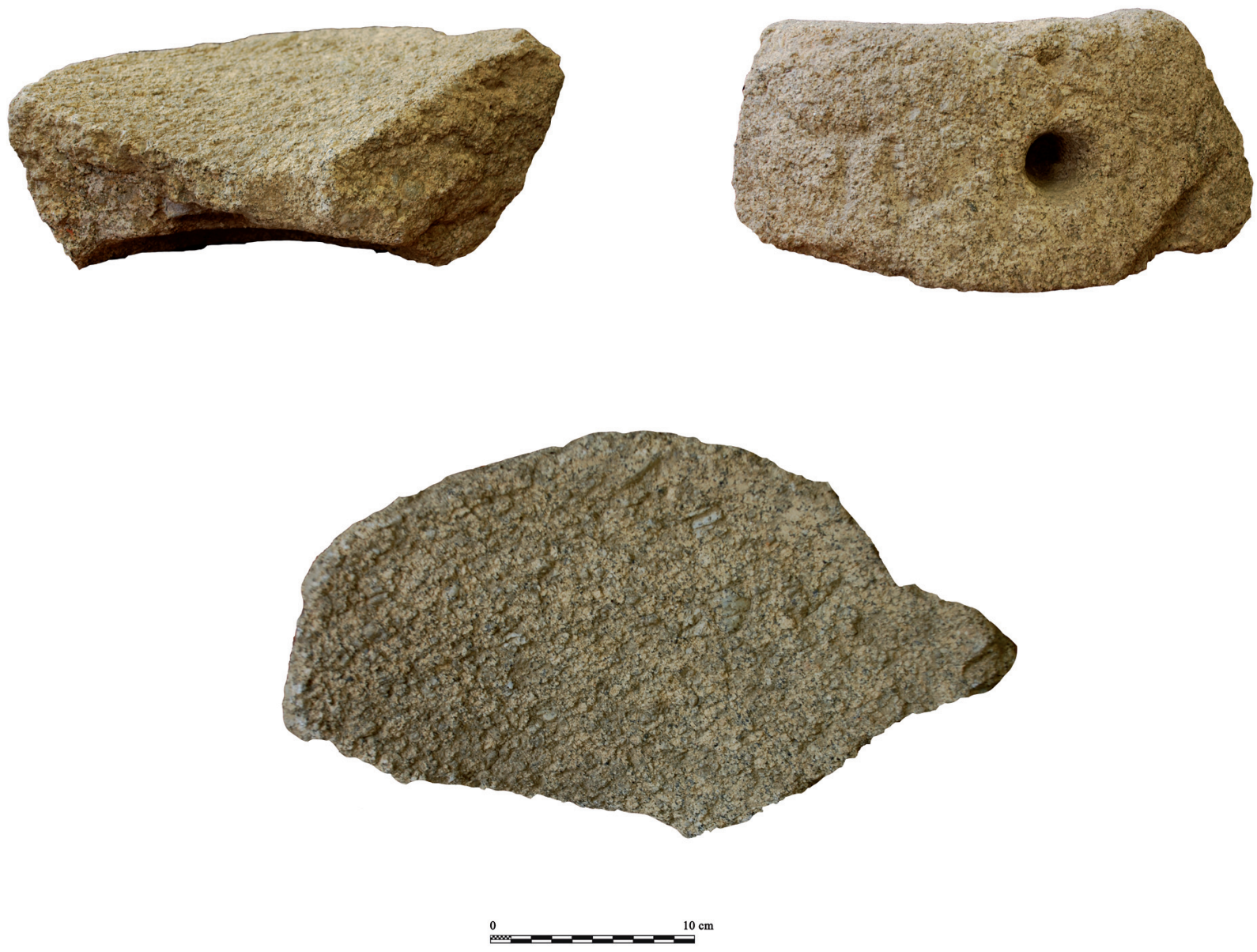

FIG. 5. Catillus con inscripción Turro procedente del castro de San Chuis. Las imágenes de la parte superior muestran el molino colocado en su posición original con visión de las dos caras de la pieza; en la imagen inferior se observa la superficie de fricción.

El origen del molino circular de mano, al que Catón se refiere como molae hispanienses (De Agr. $\mathrm{X}, 44)$ se rastrea en la Península Ibérica hacia el s. IV a. C. o quizás algo antes -hipótesis avanzada años atrás por Maya y de Blas (1973) para el mundo castreño-, si bien su generalización en el registro corresponde a momentos más avanzados de la Edad del Hierro o, con mayor frecuencia, a partir del cambio de Era (Buxó, 1991; Silva, 2007: 51).

A partir de las dimensiones de la pieza conservada es posible determinar que el molino de San Chuis debía tener un diámetro similar en la meta o piedra inferior. Esta, de forma ligeramente convexa, se adaptaba en forma al catillus, cuya parte inferior era ligeramente cóncava. El movimiento rotatorio, practicado mediante un posible astil de madera, y la fricción de ambas piedras permitiría moler un gran volumen de grano $^{6}$. Este tipo de molinos de mano giratorios

${ }^{6}$ Según Dembinska (1985: 113), el molino rotatorio manual pudo llegar a aumentar 10 veces la producción de harina respecto a los molinos de vaivén alternativo, de 0,6 $\mathrm{kg} / \mathrm{h}$ a $6 \mathrm{~kg} / \mathrm{h}$, aunque estudios etnográficos realizados sobre los molinos de vaivén estiman entre 2,7/3,6 kg de harina por hora de trabajo, es decir, que solo se duplicaría la producción (Gast, 1968). 
ofreció notables ventajas en cuanto a portabilidad y redujo el esfuerzo físico durante la molienda, al disminuir la presión de los brazos y poder permanecer erguido y no arrodillado, posición que había que mantener durante el uso de molinos precedentes, como los barquiformes o de vaivén. También hay que tener en cuenta que este tipo permite al molinero ajustar la distancia entre la meta y el catillus, de modo que le ofrece la posibilidad de producir harinas con diferente grado de extracción.

A diferencia de las molae de época posterior, el molino rotatorio de San Chuis no presenta una forma muy aplanada, perfil que va adquirir a medida que avanza la etapa imperial (Curwen, 1937: 142-144, figs. 14-23) y que permitió disminuir el coste de materia prima y, sobre todo, facilitar su traslado al reducir su peso (Moritz, 1958: 117). Molinos de este tipo están bien atestiguados en la Península Ibérica en niveles republicanos fechados c. 80 a. C., como en el campamento de Cáceres el Viejo (Ülbert, 1984: lám. 32), e incluso en contextos del s. II a. C. como los de Numantia (Schulten, 1927: 265, lám. 29, n.o 3; Schulten 1929: 73, 130, 227 y lám. 50). En Asturias constituyen un hallazgo frecuente en poblados castreños como Moriyón, Taramundi, Coaña, Pendia o el Chao Samartín, donde, con tipologías similares a la del ejemplar que nos ocupa, se documentan en horizontes de la Edad del Hierro y, principalmente, romanos (Villa, 2013: 156), por lo que, en ausencia de contexto estratigráfico, resulta comprometido establecer una adscripción cronológica precisa. Por otro lado, debemos tener en cuenta la dificultad para determinar con precisión la cronología de este tipo de mecanismos manuales, dado que son herramientas que apenas cambiaron durante siglos por la sencillez y gran utilidad del sistema empleado.

Por otro lado, el uso restringido de este tipo de molino tiene implicaciones sociales si se considera que su uso pudo estar limitado a un grupo de personas, una unidad familiar o a un individuo concreto del poblado, precisamente en un periodo en el que la radical segregación de lo privado se manifiesta como proyección consustancial del proceso de diferenciación social advertido en las comunidades castreñas a partir de su integración en el
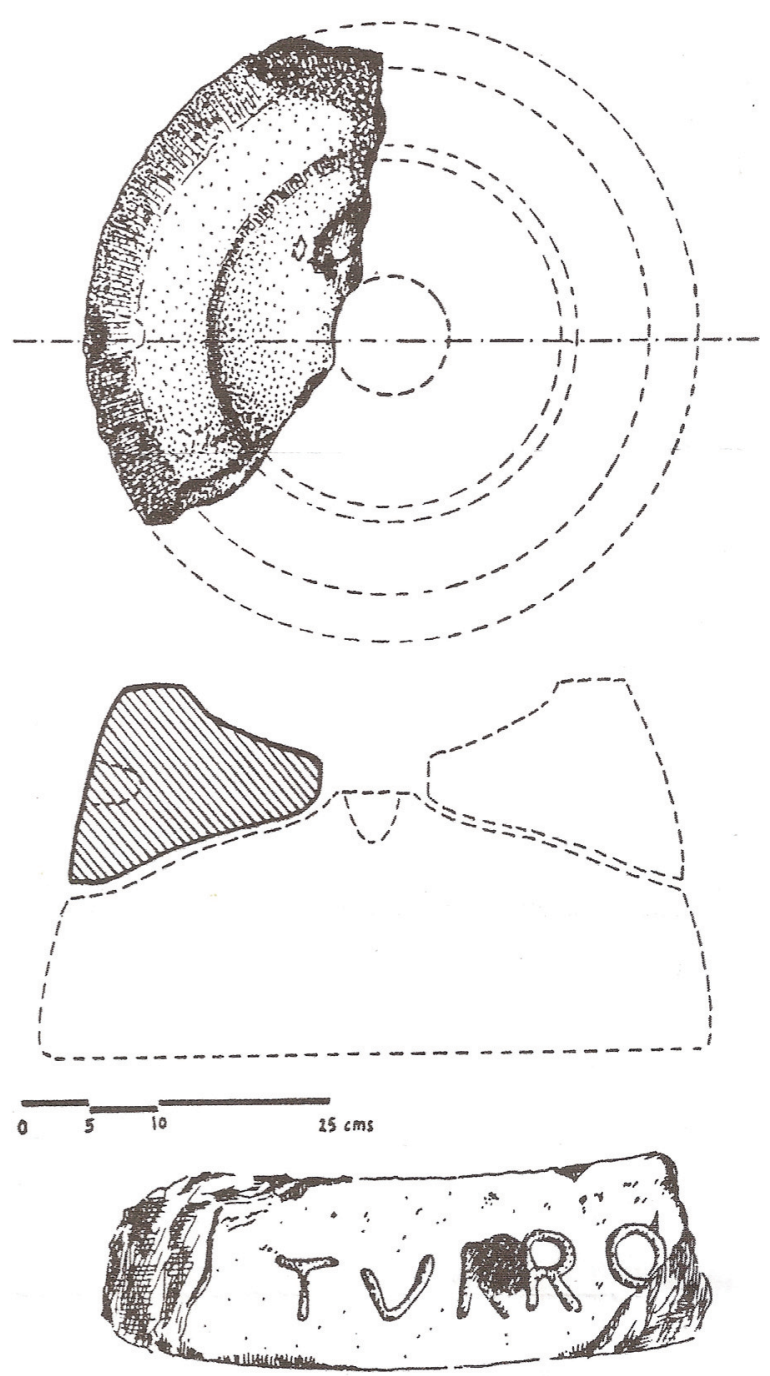

FIG. 6. Dibujo de la mola manuaria del castro de San Chuis (segun García Linares, 1984).

mundo romano. Como ya señaló Almudena Orejas, la articulación en civitates proporcionó el marco adecuado para la consolidación de aristocracias locales (Orejas, 2005: 315), cuya expresión arqueológica se manifiesta explícitamente en castros como el de Chao Samartín (Villa, 2009: 210).

Respecto a este último aspecto, la información que aporta el molino que analizamos es determinante, pues presenta la particularidad de que sirvió de soporte de la inscripción Turro. El campo epigráfico se vio posteriormente afectado por la apertura de un nuevo anclaje que recibiría un 


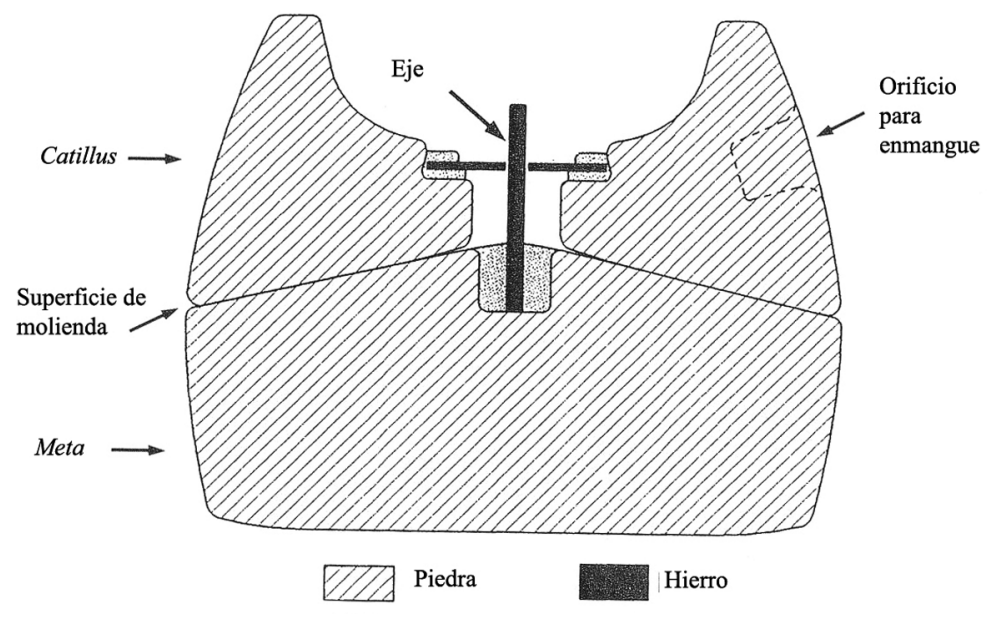

FIG. 7. Sección de un molino con catillus y meta, con eje vertical de hierro, a partir del diseño de Baatz (1994: fig. 12).

entre los antropónimos hispanorromanos a partir de las tres inscripciones del abrigo rupestre de Peñalba de Villastar, Teruel ${ }^{9}$. De igual modo, tenemos constancia de la presencia del nombre Turromus, otra acepción posible si tenemos en cuenta que la inscripción no se conserva completa debido al estado de fragmentación del molino encontrado. Este último antropónimo se ha podido documentar a partir de la inscripción que conmemoraba el monumento levantado en honor de uno de los jóvenes vadinienses que murieron en el entorno de Verdiago (León) ${ }^{10}$.

En caso de que se tratase del nombre personal de uno de los pobladores de San Chuis, deberíamos interrogarnos sobre el significa-

nuevo vástago vertical o montante, tal vez por fractura del que sirvió de encaje al asidero original (Fig. 5). Inscripciones realizadas en recipientes cerámicos localizados en yacimientos próximos se refieren a topónimos locales de época romana como (B)vroflavia, Ocela y Elanianivm (Villa y De Francisco, 2003-2004). Sin embargo, a pesar de ofrecer evidente semejanza con alguna de las poleis enumeradas por Ptolomeo, en el caso que nos ocupa nos inclinamos por aceptar que Turro posiblemente corresponde a un antropónimo, bien constatado en la Península Ibérica (Abascal, 1994: 535). Los molinos documentados hasta el momento que presentan epígrafes generalmente se asocian con unidades militares o individuos concretos, como veremos más adelante, de modo que parece más razonable pensar que el molino sería el soporte de un epígrafe que haría mención al antropónimo Turros y no a topónimos como Turriga (Ptol. II, 6, 22), población situada entre los galaicos lucenses ${ }^{7}$.

El término Turros, forma céltica que se transformará en la lengua latina en Turrus (Pérez Vilatela, 1996: 268) ${ }^{8}$, está perfectamente documentado

${ }^{7}$ Para los diversos significados del topónimo Turriga cf. Curchin, 2008: 128.

8 Tito Livio $(40,49,4)$ menciona a un tal Thurrus, o Thurus, según diversos manuscritos, como un régulo hispano durante los acontecimientos del año 179 a. C. do de la realización de una inscripción en un molino harinero. Aunque no es momento de subrayar la importancia del cereal en la alimentación de época romana, sí tenemos que incidir sobre la necesidad que sentían de individualizar o marcar la propiedad no sólo de los molinos, sino también de otros útiles asociados a prácticas relacionadas con la agricultura y la alimentación. Son muy ilustrativos de ello los morteros procedentes de campamentos romanos (Pfahl, 2004), como por ejemplo el hallado en Tréveris, datado en la segunda mitad del s. II d. C., con

9 Marcos Mas(i)mi f(ilius) / Primi [- - - / Tu]rros [Car]oq(um) (ERTe 27a; HEp 6, 1996: 916; HEp 9, 1999: 559). Sobre esta inscripción, véase Lejeune, 1955: 109; Untermann, 1977: 15-16, lám. 294; Navarro, 1994: 140143, n. ${ }^{\circ}$ 27A. Turros (ERTe 27d = HEp 9, 1999: 546); sobre este epígrafe $c f$. Lejeune, 1955: 109; Navarro, 1994: 146-147, n.o 27E, lám. XIII, 25. Turros Carorum/Cotiriqum (ERTe 27j = HEp 6, 1996: 917 = HEp 9, 1999: 556); sobre esta inscripción $c f$. Untermann, 1977: 16-20, láms. 5-6 y Navarro, 1994: 150-151, n.o 27J.

${ }_{10} \mathrm{M}$ (onumentum) / Turrom [i] / Va(diniensis) Com(i) f(ilii) / an(norum) XXV / Pude(n)s fr(atri) / pos(uit) / h(ic) s(itus) e(st) (HEp 1, 1989: 411). Otra inscripción aparecida en Huertahernando (Guadalajara) hace mención a otro posible Turromus, aunque ha sido leída como Turr(anio). O/tesgi(cum) . / Marcus (Fita, 1869: 175; Abascal, 1983: 73-74, n.o 18, fig. 4, n. ${ }^{\circ} 18$; AE 1987, 638). 


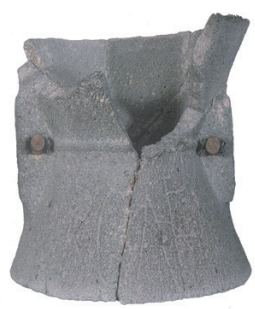

1

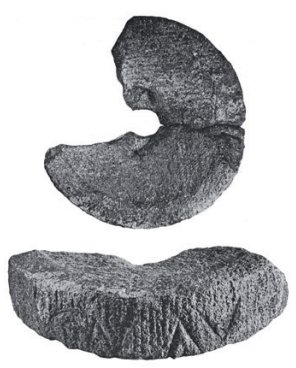

5

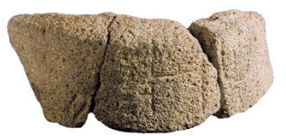

2

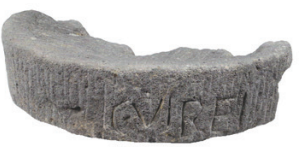

6

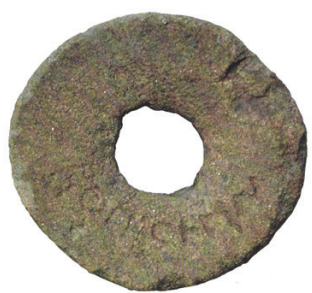

3

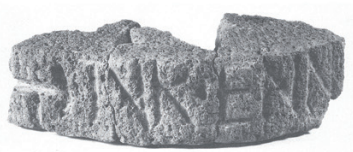

7

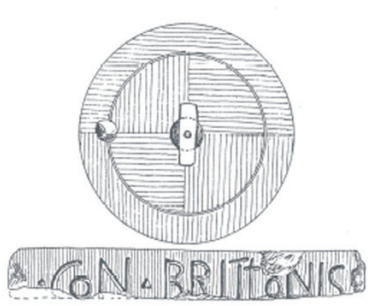

4

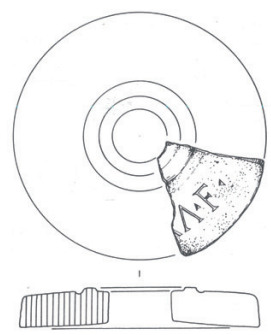

8

FIG. 8. Molinos con inscripción de diversa procedencia: 1) catillus procedente del entorno de Tarraco con inscripción RIT 814 (VV. AA., 2009: 87, fig. 6.1); 2) mola encontrada en la villa d'Els Antigons, con marca SOH (Gorostidi, 2010: 101); 3) molino procedente de la parroquia de Santa Eulalia de Esperante, Lugo (Rodríguez Colmenero, 1995: fig. 174); 4) dibujo del molino de Saalburg con inscripción con(tubernii) Britonnis (Jacobi, 1912: 21, lám. 5,40); 5) molino procedente de Rosbach con inscripción con(tubernii) Au(---) (Wabl, 1975: fig. 20); 6) molino de Estrasburgo con epígrafe c(ontubernium) Virei (Jodry, 2010: 108); 7) meta de Xanten con inscripción Tur(ma) Enni (Junkelmann, 1997: fig. 15); 8) mola procedente de Vindolanda (Welfare, 1985: fig. 61, n. ${ }^{\circ}$ 12).

inscripción del taller de Attico situado en la canabae legionis de Bonn: Atticus Fec(it)/ Kanabis Bon (nensibus) (Pfahl, 2002).

Respecto a los molinos harineros con inscripción, son bien conocidos los epígrafes presentes en las molae de Ostia o Pompeya, con marcas breves de difícil interpretación (De Rossi, 1857: 279-280; Bakker, 1999) y otros analizados recientemente procedentes de la Galia (Lacottey y Longepierre, 2011) y del ager pompeianus, en el que se localizaron un catillus y meta con marcas CE y CEA respectivamente en la villa romana de la propiedad Marchetti en Santa María La Carità (Messigno) (CIL X, 8057, 6; Stefani, 2000: fig. 66). Hasta el momento, en Hispania solo se habían documentado inscripciones realizadas sobre molinos en el entorno de Tarraco, concretamente en la zona portuaria de la ciudad donde apareció un catillus casi completo de una mola asinaria de $65 \mathrm{~cm}$ de altura y $75 \mathrm{~cm}$ de diámetro (Fig. 8, n. ${ }^{\circ}$ 1), con la inscripción RIT 814 interpretada como R(ota) Boaeti (Comes y Rodà, 2002, n. ${ }^{\circ}$ 37) que también ha sido leída como RBOAEF (VV. AA., 2009: 87, fig. 6, n. ${ }^{\circ} 1$ ) y otra en la villa de Els Antigons donde el catillus (Fig. 8, n. ${ }^{\circ}$ 2) presenta la marca $S O H$ (CIL II, 14, 2263). Posiblemente se trata de marcas de propiedad, aunque el hecho de que aparezcan en ámbito costero no implica necesariamente su comercio desde Italia, como se ha planteado recientemente (Gorostidi, 2010: 101-102); de hecho, los análisis petrográficos realizados sobre varios molinos 
romanos peninsulares determinan variados lugares de origen. Es el caso del molino de Baetulo (Badalona) posiblemente fabricado en Le Puy (Francia) o el conservado en el Museo Arqueológico de Barcelona, sin contexto arqueológico conocido, procedente de un centro productor del Rif (Williams-Thorpe, 1988: 297-298); asimismo el catillus hallado en un pistrinum de la vecina Empúries fue fabricado en Mulargia (Cerdeña) (Williams-Thorpe y Thorpe, 1989: 109), el mismo centro productor que exporta a Pollentia otros molineros harineros romanos (WilliamsThorpe y Thorpe, 1991: 152 y 157), muy posiblemente transportados como lastre en los barcos que viajaban a Hispania para aprovisionarse de grano (Williams-Thorpe, 1988: 286). También tenemos constancia del envío por vía marítima de molinos fabricados en las inmediaciones de Ullastret (Gerona) que formaban parte del cargamento del pecio de Illa Pedrosa, posiblemente con destino al vecino centro redistribuidor de Empúries (Vivar, 2004).

Mención aparte merece otro molino con inscripción aparecido en la Península Ibérica, procedente de la parroquia de Santa Eulalia de Esperante, Lugo (Fig. 8, n.o 3). Este ejemplar granítico de $40 \mathrm{~cm}$ de diámetro y $10 \mathrm{~cm}$ de altura presentaba una inscripción, de difícil lectura, toscamente grabada en la superficie cóncava de fricción, de modo que no resultaría visible ni legible durante su momento de uso. El epígrafe nos informa precisamente de su realización en el momento de su abandono: $B(e n e) O$ (pus) feci. Fin(is), es decir, 'Trabajé bien. Se acabó' (Rodríguez Colmenero, 1995: 171, fig. 174 $)^{11}$.

Es importante valorar el hecho de que la pieza proceda de un asentamiento y un territorio que conoció durante el s. I d. C. un ambiente fuertemente militarizado por las significativas implicaciones de carácter organizativo social y económico ${ }^{12}$.

${ }^{11}$ Para más información sobre esta pieza $c f$. Fernández Nieto, 2005.

12 Sobre esta cuestión cf. Morillo, 2007: 111-112; Morillo, A. y Adroher, A. (2013): "Modelos de arquitectura defensiva e implantación territorial de los campamentos republicanos en Hispania”. En Mataloto, R.; Roque, C. y Mayoral, V. (eds.): Paisajes agrarios de la Romanización II. Anejos de Archivo Español de Arqueología. Madrid: CSIC, en prensa.
La información que la pieza nos aporta en esta cuestión es fundamental, pues la inscripción no alude a unidades básicas del ejército ni a escalas o grados de la jerarquía castrense. En cambio, en algunos yacimientos de carácter eminentemente militar, como los castra o campamentos, se ha localizado este tipo de piezas con inscripciones relativas a contubernia, es decir, agrupaciones militares formadas por ocho soldados de infantería que compartían, además de tienda, la impedimenta común como las molae (Daremberg y Saglio, 1877: 1489). Así se ha podido constatar a partir de los molinos harineros encontrados en fuertes militares de Germania, concretamente en Saalburg (Fig. 8, n.o 4), donde la inscripción decía con(tubernii) Britonnis (CIL XIII, 11954a; Jacobi, 1912: 21, lám. 5, n. ${ }^{\circ}$ 40); en Rosbach, en el que se halló un catillus (Fig. 8, n. ${ }^{\circ}$ ) con la inscripción con(tubernii) $A u$ (-) (Wahl, 1975: fig. 20), o en Estrasburgo (Fig. 8, n. ${ }^{\circ}$ 6), correspondiente a un c(ontubernium) Virei, es decir, de Vireo (Jodry, 2007: 26; 2010: 107-108). También se han localizado en asentamientos militares como Xanten donde apareció una meta del s. I d. C. (Fig. 8, n. ${ }^{\circ}$ 7) que tiene la inscripción $\operatorname{Tur}(m a)$ Enni, es decir, 'el escuadrón de caballería de Ennius' (Junkelmann, 1997: 33, fig. 15). En Chesterholm (Vindolanda) se han localizado al menos tres molinos con inscripción (Birley, 1932: 219; Welfare, 1985: 159), de los que uno hace mención a una centuria -se conserva la letra $C$ (enturia) seguida de $A D-$ (Watts, 2011: 342) y otra mola (Fig. 8, n. ${ }^{\circ}$ ) con un epígrafe en la parte superior del que se ha perdido el comienzo del texto, pero conserva dos letras separadas por interpunción triangular $-A$ sin travesaño y $F-$ (Welfare, 1985: 159, fig. 61, n. ${ }^{\circ}$ 12).

Diferente es el molino localizado en 1895 en Greatchesters, uno de los fuertes del Muro de Adriano, pues presenta una inscripción con el nombre del centurión seguido de la palabra Molavii (Watts, 2011: 342). Aunque es cierto que este epígrafe alude a una persona en concreto, no podemos olvidar que hace referencia a su condición de centurión. En otros asentamientos incluso se ha podido determinar a partir de la epigrafía la propiedad de algunos objetos de bronce o cerámicos a determinadas centuriae y contubernia de las tropas asentadas (Wahl, 1975: 286). 
En este sentido, el hecho de que el epígrafe del molino astur se refiera a una persona y no a una unidad militar podría ser indicativo, a tenor de la mayoría de los ejemplares de molae con inscripciones aparecidas, de la ausencia en este momento de unidades militares asentadas en este asentamiento, o al menos que respondan a esta ordenación militar. Este dato no excluye, no obstante, el ambiente ampliamente militarizado, bien documentado por los abundantes testimonios aparecidos, especialmente, en el castro de Chao Samartín, en Grandas de Salime, en el propio San Chuis y en otros castros de la comarca, que incluyen desde importaciones cerámicas hasta armamento y numerario.

\section{Consideraciones finales}

El fragmento de catillus localizado en el castro de San Chuis es la pieza activa de un molino rotatorio o rotativo de época romana. La ausencia de contexto arqueológico y la dificultad para adscribir este tipo de pieza a un periodo concreto impiden afinar la cronología del molino. Este tipo de mola manuaria está bien documentado en poblados castreños -Moriyón, Taramundi, Coaña, Pendia o el Chao Samartín-, tanto en contextos de la Edad del Hierro como altoimperiales, pero el que aquí analizamos presenta la particularidad de portar una inscripción -Turro- que confirma su datación romana.

El hecho de que el epígrafe esté perforado posiblemente se justifique por la necesidad de practicar un nuevo anclaje ante la fractura del original que debió hallarse en otra sección del molino no conservada; así pues, ese orificio debió alojar el montante para accionar la mola.

Respecto al significado de la inscripción, ante las distintas posibilidades interpretativas, consideramos que Turro puede corresponde a un antropónimo perfectamente atestiguado en Hispania. Esto contrasta con el hecho de que las inscripciones sobre molinos documentados hasta el momento en otros asentamientos generalmente aluden a unidades militares concretas -contubernium, centuria, turma-, o bien son marcas de difícil interpretación o responden a invocaciones realizadas ya en el ámbito civil después de la vida útil del molino; lo habitual es que en los casos en que el epígrafe se refiere a un individuo se hace mención a su categoría militar en el ámbito castrense. Para la pieza aparecida en el castro de San Chuis todo parece indicar que la mola manuaria pertenecía a una persona concreta; puesto que no hace referencia a unidades ni categorías militares, planteamos la posibilidad de que esto sea indicativo de la ausencia en este momento de unidades militares asentadas en dicho castro o de organizaciones que respondan a esta ordenación militar, si bien este dato no excluye que el poblado se encuentre en un ambiente ampliamente militarizado.

\section{Bibliografía}

ABASCAL, J. M. (1983): "Epigrafía romana de la provincia de Guadalajara", Wad-al-Hayara, 10, pp. 49-116.

ABASCAL, J. M. (1994): Los nombres personales en las inscripciones latinas de Hispania. Murcia.

Alonso, N. (1997): "Origen y expansión del molino rotativo bajo en el Mediterráneo occidental". En Meeks, D. y García, D. (eds.): Techniques et économie antiques et médiévales. Le temps de l'innovation. Paris, pp. 15-19.

Alonso, N. (1999): De la llavor a la farina: els processos agricoles protohistòrics a la Catalunya Occidental. Lattes.

BaAtz, D. (1994): "Die Handmühlen". En HelLenkemper, G.; Bauchhenss, G.; Prittwitz, H. y Gaffron, H. (eds.): Das Wrack: Der antike Schiffsfund von Mahdia. Köln, pp. 97-103.

BAATZ, D. (1995): "Die Wassermühle bei Vitruv X, 5, 2. Ein archäologischer Kommentar”, Saalburg Jahrbuch, 48, pp. 5-18.

BAKKER, J. T. (1999): The mills bakeries of Ostia. Amsterdam.

Birley, E. (1932): "Excavations at ChesterholmVindolanda", Archaeologia Aeliana, serie 4, 9, pp. 219-221.

Brunet, M. (1997): "Le Moulin Délien”. En Meeks, D. y GARCíA, D. (eds.): Téchniques et économie antiques et médiévales: Le temps de l'innovation. Paris, pp. 29-38.

BuxÓ, R. (1991): "Aperçu sur les artefactas associés à la transformation des céréales en préhistoire. État des études en Espagne méditerranéenne". En Sigaut, F. y Fournier, D. (eds.): La préparation alimentaire des céréales. Estrasburgo, pp. 17-24.

CARretero, S. (2000): El campamento romano del Ala II Flavia en Rosinos de Vidriales (Zamora): la cerámica. Zamora.

CARrocera, E. (1995): "El territorio de los astures: los castros”. En Fernández OchOA, C. (coord.): 
Astures. Pueblos y Culturas en la frontera del Imperio Romano. Gijón, pp. 53-65.

Comes, R. y RodÀ, I. (eds.) (2002): Scripta manent. La memoria escrita de los romanos. Barcelona: MAC.

Curchin, L. A. (2008): "Los topónimos de la Galicia romana: nuevo studio", Cuadernos de Estudios Gallegos, LV, n.o 121, pp. 109-136.

CurTis, R. I. (2001): Ancient Food Technology. Leiden.

Curwen, E. C. (1937): "Querns", Antiquity, 11, pp. 133-151.

DaremberG, Ch. V. y Saglio, E. (1877): Le Dictionnaire des Antiquités Grecques et Romaines. Paris.

De Rossi, G. B. (1857): "Antichi mulini in Roma en el Lazio", Annali dell'Istituto di Corrispondenza Archeologica di Roma, 1857, pp. 274-281.

DEMBINSKA, M. (1985): "Différents systèmes de mouture en Europe de l'Est au Moyen-Âge". En GAST, M.; Sigaut, F. y Beutler, C. (eds.): Les techniques de conservation des graines à long terme, 3 (1). Paris, pp. 109-118.

FernÁndez Nieto, F. J. (2005): “Un catillus de Lugo y las virtudes mágicas de las soleras y volanderas in finibus", Revista Internacional de Investigación sobre Magia y Astrología Antiguas, 5, pp. 343-354.

Fernández-Posse, M. D. (2002): “Tiempos y espacios en la Cultura Castreña”. En De BLAS, M. A. y VILLA, A. (eds.): Los poblados fortificados del noroeste de la Peninsula Ibérica: formación y desarrollo de la cultura castreña. Navia, pp. 81-95.

FiTA, F. (1869): "Inscripciones de Huerta-Hernando, a una y media legua de Buenafuente", Boletín de la Real Academia de la Historia, 28, p. 175.

García Linares, A. (1984): "Hallazgo de un fragmento de molino circular epigráfico, en El Castro de San Chuis", La Maniega, nov.-dic., pp. 10-11.

Gast, M. (1968): Alimentation des populations de l'Ahaggar. Étude ethnographique. Mémoires du Centre de Recherches Anthropologiques Préhistoriques et Etnographiques, 8. Paris.

GiL, F. y Villa, A. (2006): "La circulación monetaria en los castros asturianos". En García-Bellido, M. P. (coord.): Moneda y ejército en la Hispania altoimperial. Madrid: CSIC, pp. 501-519.

Gorostidi, D. (2010): Ager Tarraconensis, 3. Les inscripcions romanes (IRAT). Documenta, 16. Tarragona.

GuÉRIN, P. (1999): "Hogares, molinos, telares... El Castellet de Bernabé y sus ocupantes", Arqueología Espacial, 21, pp. 85-89.

Hevia, S. y Montes, R. (2009): "Cerámica común romana altoimperial de fabricación regional del Chao Samartín (Grandas de Salime, Asturias)", Cuadernos de Prehistoria y Arqueología de la Universidad Autónoma de Madrid, 35, pp. 27-187.
JACOBI, H. (1912): "II. Die Ausgrabungen. 1. Kastell Saalburg", Saalburg Jahrbuch, 3, pp. 6-26.

JODRY, F. (2007): "À propos d'une meule militaire", Instrumentum, 26, p. 26.

JODRY, F. (2010): “Un moulin par contubernium!". En Schnitzler, B. y Kuhnle, G. (dirs.): StrasbourgArgentorate: un camp légionnaire sur le Rhin, Ier au VIe siècle après J.-C. Estrasburgo, pp. 107-108.

JoRDÁ, F. (1990): "Informe preliminar sobre las excavaciones arqueológicas en el Castro de San Chuis (Beduledo, Allande) Asturias. Campaña de 1986", Excavaciones Arqueológicas en Asturias, 1983-86, 1, pp. 153-156.

Junkelmann, M. (1997): Panis militaris. Die Ernährung des römischen Soldaten oder der Grundstoff der Macht. Mainz am Rhein.

Lacottey, L. y LongepierRe, S. (2011): "Pompeian millstones in France". En Williams, D. y PeACOCK, D. (eds.): Bread for the People: The Archaeology of Mills and Milling. Oxford, pp. 97-116.

Lejeune, M. (1955): Celtibérica. Salamanca.

Marcos, A. y Ruiz, F. (1978): San Martín de Oscos. Mapa Geológico de España E. 1:50.000. Madrid.

MaYA, J. L. y DE Blas, M. A. (1973): "El molino del castro de La Picona y notas sobre la introducción de los tipos giratorios en Asturias", Boletín del Instituto de Estudios Asturianos, 80, pp. 717-722.

Morel, J.-P. (2001): "Aux origins du moulin rotatif? Une meule circulaire de la fin du vie siècle avant notre ére à Carthage". En BRUN, J.-P. y JOCKEY, P. (eds.): Technai: Tecnicques et sociétés en Méditerranée. París, pp. 241-250.

Morillo, Á. (2007): "El ejército romano en España". En Morillo, Á. (ed.): El ejército romano en Hispania. Guía arqueológica. León, pp. 87-112.

MoriTz, L. A. (1958): Grain-mills and flour in classical antiquity. Oxford.

NAVARro, M. (1994): La epigrafía romana de Teruel. Teruel.

Oliveira, F.; Queiroga, F. y Pereira, A. (2007): "Pao de bolota na cultura castreja". En CoElHo, A. (coord.): Pedra Formosa. Arqueologia experimental. Vilanova de Famalição, pp. 122-131.

Orejas, A. (2005): "El poblamiento romano en los distritos mineros del Noroeste". En FernándeZ Ochoa, C. y García, P. (eds.): Unidad y diversidad en el Arco Atlántico en época romana. III Coloquio Internacional de Arqueología en Gijón. Gijón, pp. 309-319.

PéreZ Vilatela, L. (1996): "Inscripciones celtibéricas inéditas de Peñalba”. En VILlar, F. y ENCARNaÇão, J. (eds.): La Hispania prerromana. VI Coloquio sobre lenguas y culturas prerromanas. Salamanca, pp. 247-277. 
PfaHL, S. (2002): "Von Bonn nach Trier. Ein mortarium des ATticVs aus den KANABAE (LEGIONIS)", Trierer Zeitschrift, 65, pp. 91-98.

Pfahl, S. (2004): "Mortaria mit Namenstempel aus dem Limesgebiet”, Saalburg Jahrbuch, 54, pp. 61-92.

Quesada, F.; Kavanagh de Prado, E. y Lanz, M. (2014): "Los molinos del yacimiento del Cerro de la Cruz (Almedinilla, Córdoba): clasificación y análisis de los ejemplares de época ibérica y emiral", Spal, 23, pp. 83-120.

http://dx.doi.org/10.12795/spal.2014.i23.05

RodríGuez COLMENERo, A. (1995): "La amistad entre una ama de casa y su molino". En Lucus Augusti, urbs romana: los origenes de la ciudad de Lugo. Lugo, p. 171.

Schulten, A. (1927): Die Ergebnisse der Ausgrabungen 1905-1912. Numantia III. Die Lager des Scipio. München.

Schulten, A. (1929): Die Ergebnisse der Ausgrabungen 1905-1912 Numantia IV. Die Lager bei Renieblas. München.

Silva, A. C. F. (2007): Pedra Formosa. Vila Nova de Famalição.

STEFANI, G. (2000): "Il ciclo del pane in época romana”. En Guzzo, P. G. (dir.): Casali di ieri, casali di oggi: architetture rurali e tecniche agricole nel territorio di Pompei e Stabiae. Naples, pp. 123-128.

ÜlberT, G. (1984): Cáceres el Viejo. Ein spätrepublikanisches Legionslager in Spanisch-Extremadura. Madrider Breitäge, 11. Mainz am Rhein.

UNTERMANN, J. (1977): "En torno a las inscripciones rupestres de Peñalba de Villastar", Teruel, 57-58, pp. 5-21.

Villa, A. (2007): "El Pico San Chuis: reseña de un yacimiento pionero en la investigación castreña en Asturias", Sautuola, 12, pp. 167-179.

Villa, A. (2009): “¿De aldea fortificada a Caput Civitatis? Tradición y ruptura en una comunidad castreña del s. I d. C.: el poblado de Chao Sanmartín (Grandas de Salime, Asturias)", Cuadernos de Prehistoria y Arqueología de la Universidad Autónoma de Madrid, 35, pp. 7-26.

VILlA, A. (2010): "El oro en la Asturias antigua: minería y orfebrería en torno al cambio de Era". En Fernández Tresguerres, J. A. (ed.): Cobre y Oro. Minería y metalurgia en la Asturias prehistórica $y$ antigua. Oviedo: RIDEA, pp. 83-125.

Villa, A. (2013): "El Castro de Coaña". En De Blas, M. A. (coord.): De neandertales a albiones. Cuatro lugares esenciales en la Prehistoria de Asturias. Oviedo: RIDEA, pp. 139-187.

Villa, A. y De Francisco Martín, J. (2003-2004): "Toponimia de algunos asentamientos castreńos en el Occidente de Asturias: Nuevos datos epigráficos sobre vasos cerámicos", Revista de Filoloxía Asturiana, 3-4, pp. 11-30.

Villa, A. y GiL, F. (2006): "Castros asturianos con presencia militar. Aproximación al modelo de implantación de Roma en Asturias". En GARCÍABELLIDO, M. P. (coord.): Los campamentos romanos en Hispania (27 a.C.-192 d.C): el abastecimiento de moneda. Madrid: CSIC, vol. 2, pp. 493-500.

Villa, A. y MenéndeZ, A. (2011): "Estudio cronoestratigráfico de las murallas del castro de San Chuis, en San Martín de Beduledo (Allande, Asturias)", Boletín del Real Instituto de Estudios Asturianos, 173-174, pp. 159-179.

Villa, A.; MenÉndez, A. y Gil, F. (2006): "Fortificaciones romanas en el castro de Chao Samartín (Grandas de Salime, Asturias)". En Morillo, Á. (coord.): Arqueología Militar Romana en Hispania. Producción y abastecimiento en el ámbito militar. León, pp. 581-599.

VIVAR, G. (2004): "El transporte de redistribución en el nordeste de la Península Ibérica en época tardorrepublicana: el ejemplo de los yacimientos de Illa Pedrosa y Cala Galladera”. En ZEvI, A. G. y TuRCHETTI, R. (eds.): Méditerranée occidentale antique: les échanges. Marseille, pp. 101-112.

Vv. AA. (2009): Tarraco, pedra a pedra. Catàleg de l'exposició. Tarragona.

WAHL, J. (1975): "Untersuchungen an Wp. 4-5Steinturm. Fragment eines Handmühlsteins mit militärischer Besitzerinschrift. Zur Besatzung der Wachttürme am Limes", Fundberichte aus Hessen, 15 , pp. 283-296.

WatTS, S. (2011): "The function of querns". En Williams, D. y Peacock, D. (eds.): Bread for the People: The Archaeology of Mills and Milling. Oxford, pp. 341-348.

Welfare, A. T. (1985): "The objects of stone and tile". En Bidwell, P. T.: The Roman fort of Vindolanda at Chesterholm, Northumberland. London, pp. 130-151.

WiLliams-ThORPE, O. (1988): "Provenancing and archaeology of Roman millstones from the Mediterranean area", Journal of Archaeological Science, 15, pp. 253-305. http://dx.doi.org/10.1016/0305-4403(88)90066-0

Williams-Thorpe, O. y Thorpe, R. S. (1989): "Provenancing and archaeology of Roman millstones from Sardinia (Italy)", Oxford Journal of Archaeology, 8 (1), pp. 89-117. http://dx.doi.org/10.1111/j.1468-0092.1989.tb00193.x

Williams-ThorPe, O. y THORPE, R. S. (1991): "The import of millstones to Roman Mallorca", Journal of Roman Archaeology, 4, pp. 152-159. 